\title{
Are CEOs expected utility maximizers?
}

\author{
John A. List ${ }^{\mathrm{a}, \mathrm{b}}$, Charles F. Mason ${ }^{\mathrm{c}, \mathrm{d}, *}$ \\ a University of Chicago, United States \\ ${ }^{\mathrm{b}}$ NBER, United States \\ ${ }^{c}$ University of Wyoming, United States \\ d Cambridge University, United Kingdom
}

\section{A R T I C L E I N F O}

\section{Article history:}

Available online $\mathrm{xxxx}$

\section{JEL classification:}

C91

D81

\section{Keywords:}

Decision making under uncertainty

High stakes

Experiments

\begin{abstract}
A B S T R A C T
Are individuals expected utility maximizers? This question represents much more than academic curiosity. In a normative sense, at stake are the fundamental underpinnings of the bulk of the last halfcentury's models of choice under uncertainty. From a positive perspective, the ubiquitous use of benefitcost analysis across government agencies renders the expected utility maximization paradigm literally the only game in town. In this study, we advance the literature by exploring CEO's preferences over small probability, high loss lotteries. Using undergraduate students as our experimental control group, we find that both our CEO and student subject pools exhibit frequent and large departures from expected utility theory. In addition, as the extreme payoffs become more likely CEOs exhibit greater aversion to risk. Our results suggest that use of the expected utility paradigm in decision making substantially underestimates society's willingness to pay to reduce risk in small probability, high loss events.
\end{abstract}

(C) 2009 Published by Elsevier B.V.

\section{Introduction}

Government officials around the globe are currently mapping a course of action to deal efficiently with terrorism risk, chemical plant security, potential nuclear accidents, climate change, and biodiversity loss. One common thread linking these high-profile issues is that most experts agree they are small probability, high loss events. In the US, the Bush Administration and both Houses continue to debate the most proficient level of government action in each of the specific cases with one ubiquitous line of reasoning: the expected costs and expected benefits of the various policy proposals must be compared and contrasted. Such an approach, which has become the hallmark of public policy decision making around the globe, implicitly assumes that citizens maximize expected utility (see, e.g. Chichilnisky and Heal, 1993).

While the expected utility (EU) approach conveniently models probabilistic choice, a great deal of experimental evidence calls into question the empirical validity of the EU maximization paradigm (see, e.g. Machina, 1987; Viscusi, 1992; Thaler, 1992). ${ }^{1}$

\footnotetext{
* Corresponding address: Universtiy of Wyoming, Department of Economics and Finance, Laramie, WY 82071-3985, United States. Tel.: +1 307 766 2178; fax: +1 307 7665090.

E-mail address: bambuzlr@uwyo.edu (C.F. Mason).

1 Perhaps of greater importance for our purposes is that the preponderance of evidence points to a tendency for the EU model to fail when the uncertain events include an outcome that is relatively unlikely to occur, but has large payoff implications (Lichtenstein et al., 1978; Baron, 1992).
}

An influential group of commentators has argued that the experimental evidence warrants a major revision to the current public policy framework, but it is important to recognize that the body of evidence is based largely on student behavior over positive outcomes (see, e.g. Starmer, 2000). Since many important public policies involve small probability, high loss events, it is important to understand individual preferences over lotteries for considerable losses; and since the cost-benefit approach is linked critically to ability to pay, it is of great import to understand affluent citizens' preferences over small probability, high loss events.

With the goal of procuring a subject pool that would be on the opposite end of the "experience spectrum" from undergraduate students in terms of evaluating and dealing with risky outcomes, while at the same time allowing an analysis of high stakes decision making among the relatively affluent, we set out searching for such opportunities. Our search concluded when board members at the Costa Rica Coffee Institute (ICAFE) extended an invitation to their annual conference, at which we would have (i) access to chief executive officers (CEOs) and (ii) conference time and floor space on ICAFE grounds to carry out experiments. To ensure that the CEOs were compelled to treat the experimental lottery outcome as a true loss, we had them participate in other unrelated experiments over a one-hour period to earn their initial endowments. Our experiment, therefore, could be thought of as a first test of the empirical accuracy of the expected utility model over losses for agents who are players in the international marketplace. In light of the recent arguments in Harrison and List (2004) and Levitt and List (2007), 


\section{$A$ RTICLE IN PRESS}

such an artefactual field experiment represents a useful advance in the area of risky decision making. ${ }^{2}$

Making use of Costa Rican undergraduate students as our experimental control group, we find that both cohorts exhibited behavior inconsistent with expected utility theory. In fact, observed departures from expected utility theory suggest that a policy approach based solely on expected benefits and expected costs would significantly understate society's actual willingness to pay to reduce risk in low probability, high loss situations. Our results indicate that for a typical CEO, willingness to pay to reduce the chance of the worst event is very similar to the corresponding willingness to pay for a typical student. Yet, we do find some important differences in behavior across subject pools; for example, as the extreme events become more likely CEOs exhibit greater aversion to risk.

The remainder of our study is crafted as follows. Section 2 provides a brief background and summarizes our experimental design. In Section 3, we present our empirical findings. Section 4 concludes.

\section{Background and experimental design}

We begin with a brief discussion of the traditional expected utility model and note some recent literature concerning violations of the underlying modeling assumptions. Consider three events, $x_{1}, x_{2}$, and $x_{3}$, where the monetary magnitudes of the events are situated as follows: $x_{1}<x_{2}<x_{3}$. If $p_{i}$ is the probability that outcome $x_{i}$ will be realized, then the lottery $\mathbf{p}$ is the vector of probabilities $\left(p_{1}, p_{2}, p_{3}\right)$. The $\mathrm{EU}$ hypothesis postulates that there is an increasing function $u(\bullet)$ over wealth such that an agent prefers lottery $\mathbf{p}$ to lottery $\mathbf{q}$ if and only if $V(\mathbf{p})>V(\mathbf{q})$, where

$V(\mathbf{p})=\sum_{i=1}^{3} u\left(x_{i}\right) p_{i}$

Behind this framework lie three axioms: ordering, continuity, and independence, which together imply that preferences can be represented by a numerical utility index. We focus exclusively on the third axiom, as it is the independence axiom that implies linear indifference curves in probability space (i.e., indifference curves are parallel straight lines in the Marschak-Machina triangle (Marschak, 1950)).

Several experimenters have tested this axiom using experiments with degenerate gambles over certain outcomes. ${ }^{3}$ For example, Harless (1992), Hey (1995), and Hey and Orme (1994) present econometric estimates of indifference curves under risk at the individual level (in gain space). Many of the proposed variants on expected utility maximization imply a representation that is quadratic in probabilities (as opposed to the linear representation induced by expected utility). The general conclusion is that neither expected utility theory nor the non-expected utility alternatives do a satisfactory job of organizing behavior at the individual level. In particular, considering shapes of indifference curves in the Marschak-Machina triangle, some "stylized facts" concerning individual choice include: (i) indifference curves vary in slope from risk-averse to risk-seeking; (ii) indifference curves are not straight, and indeed fan in and out in a systematic, complex pattern; and (iii) indifference curves are most curved near the boundaries of the

\footnotetext{
2 Making use of professionals in controlled experiments is not novel to this study - see List's field experiment website that lists more than 100 artefactual field experiments as well as reviews in Harrison and List (2004) and List (2006). For example, Burns (1985) uses Australian wool traders to explore bidding patterns in auctions. More recently, Fehr and List (2004) use these same Costa Rican CEOs to explore trust and trustworthiness; Haigh and List (2005) use traders from the Chicago Board of Trade to explore myopic loss aversion.

3 For an insightful overview see Starmer (2000).
}

triangle. Similar patterns have also been found in market settings: Evans (1997) examined the role of the market in reducing expected utility violations and found that while it did indeed reduce violations, the improved performance may have been induced by the market price selection rules.

To our best knowledge, the experiments we design and examine below are novel to the literature in that they are based on lotteries over losses that span the individual experience spectrum (in terms of evaluating and dealing with risky outcomes), while simultaneously providing a glimpse at preferences of the relatively affluent over high stakes. Such an artefactual field experiment has not been attempted to our best knowledge. By examining the pattern of subjects' choices, we can determine whether their choices are consistent with the expected utility representation. And, we are provided with a sense of the preference structure of economic actors who are in prestigious roles within the international economy. Beyond its practical import, we find such an analysis important in establishing a dialogue on how self-selection effects might importantly influence behaviors. As Fehr and List (2004) note, one common criticism of laboratory experiments is that the use of a student subject pool might compromise generalizability.

\subsection{Experimental design}

Our student lottery sessions included 101 subjects from the undergraduate student body at the University of Costa Rica. Each student session was run in a large classroom on the campus of the University of Costa Rica. To ensure that decisions remained anonymous the subjects were seated far apart from each other. The CEO subject pool included 29 CEOs from the coffee beneficio (coffee mill) sector who were gathered at the Costa Rica Coffee Institute's (ICAFE) annual conference. ${ }^{4}$ The conference is funded by ICAFE and presents the CEOs with information related to the most recent technological advances in the coffee processing sector, regulations within Costa Rica as well as abroad, and general market conditions, among other agenda items. Each of the CEO treatments was run in a large room on-site at the institute. As in the case of the students, communication between the subjects was prohibited and the CEOs were seated such that no subject could observe another individual's decision. Our student treatment was run in the two days directly preceding the CEO treatment.

To begin the experiment, subjects signed a consent form and were informed that the entire experiment would last about two hours, and that after all parts of the experiment were completed, their earnings (losses and gains) would be determined and would constitute their take-home pay. In the first part of the experiment, student (CEO) subjects participated in unrelated treatments (reported in Fehr and List, 2004) in which they earned at least $\$ 10(\$ 100)$.

Once subjects had earned their funds, we informed them that they were now entering the final stage of the experiment, and that this stage would present subjects with 40 pairs of lotteries, which we called "options" (see Appendix C). Following the notation above, we defined the lotteries as follows: $x_{1}, x_{2}$, and $x_{3}$ represent the magnitudes of the three losses, where $x_{1}<x_{2}<x_{3}$ - suggesting that the first possible outcome entails the largest loss, while the third outcome entails the smallest loss. In our experiment, we make $x_{1}=\$ 80, x_{2}=\$ 30$, and $x_{3}=\$ 0$ for CEOs and

\footnotetext{
4 ICAFE was created in 1948, and is a semi-autonomous institution in charge of providing technical assistance, undertaking field research, supervising receipts and processing of coffee, and recording export contracts.
} 


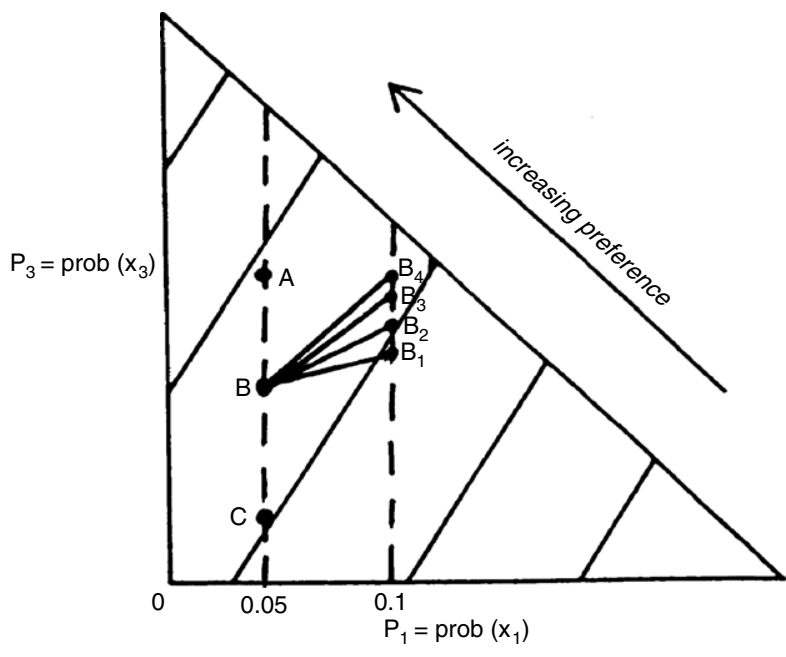

Fig. 1. Comparison of lotteries in our experimental design.

$x_{1}=\$ 8, x_{2}=\$ 3$, and $x_{3}=\$ 0$ for students. Given what we observed during the experiment and received in feedback via postexperimental interviews, we are confident that both subject pools considered these stake levels as considerable. ${ }^{5}$

We built the set of lotteries around three reference lotteries, which we selected to reflect specific low probability risk scenarios. In lottery A, the 'less bad' outcome obtains with a small probability. This describes a situation in which both the worst outcome and the less bad outcome are not very likely to occur. In lottery B, the less bad outcome is more likely than the other events, but still is not highly probable. This corresponds to a situation with a substantial chance of medium-size losses. In lottery $\mathrm{C}$, losses are quite likely, but they are overwhelmingly more likely to be modest than large. These different scenarios are suggestive of different types of potential catastrophes.

Fig. 1 illustrates our method for selecting lotteries. The three probabilities for lottery $A$ in this example are $p_{1}=0.05, p_{2}=0.35$, and $p_{3}=0.6$. The three probabilities for $\mathrm{B}$ are $p_{1}=0.05, p_{2}=$ 0.55 , and $p_{3}=0.4$. The three probabilities for $C$ are $p_{1}=0.05$, $p_{2}=0.75$, and $p_{3}=0.2$. Notice that in each of these three lotteries, the probability of the worst event (lose $\$ 80$ ) is quite small. Each of these reference lotteries was compared to twelve other points; four where $p_{1}$ was reduced to 0.01 , four where $p_{1}$ was increased to 0.1 , and four where $p_{1}$ was increased to 0.2 . The decrease in $p_{1}$ from 0.05 to 0.01 was combined with a decrease in $p_{3}$. Conversely, the increase in $p_{1}$ from 0.05 to either 0.1 or 0.2 was combined with an increase in $p_{3}$. The decreases (and increases) in $p_{3}$ followed a specific path. For example, the four points where $p_{1}$ was increased from 0.05 to 0.1 are labeled as points B1 $(0.1,0.49,0.41), B 2(0.1$, $0.45,0.45), \mathrm{B} 3(0.1,0.4,0.5)$, and B4 $(0.1,0.3,0.6)$.

We ran the experiment in four stages. In the first stage the monitor read the instructions, while subjects followed along on their copy. ${ }^{6}$ Subjects were told that no communication between them would be allowed during the experiment. After reading the

\footnotetext{
5 Note that it is the loss associated with an event, and not the expected loss that is large. This interpretation of large-stakes events is in keeping with the traditional approach to modeling decision making under uncertainty (Hirshleife and Riley, 1992).

6 See Appendix A for a copy of the experimental instructions, which followed Mason et al. (2005). Note that we took great care to ensure that the experimental instructions were understood. They were first written in English and then translated into Spanish. This translation was performed by a Costa Rican expert. To control for translation biases, a different translator located in Arizona then translated the Spanish instructions back into English. We then cross-checked the translated experimental instructions for internal consistency.
}

instructions and having all of their questions answered, subjects began Stage 2. In Stage 2, each subject was given an option sheet with 40 pairs of options, and circled his or her preferred option for each of the 40 pairs; thus our experimental design provided us with more than 1000 (4000) CEO (student) lottery choices. Each option was divided into 3 probabilities:

$p_{1}$ is the probability of losing $\$ 80$;

$p_{2}$ is the probability of losing $\$ 30$; and

$p_{3}$ is the probability of losing $\$ 0$.

For example, if an option has $p_{1}=20 \%, p_{2}=50 \%$, and $p_{3}=30 \%$, this implies a subject has a $20 \%$ chance to lose $\$ 80$, a $50 \%$ chance to lose $\$ 30$, and a $30 \%$ chance to lose $\$ 0$. For each option, the three probabilities always sum to $100 \%\left(p_{1}+p_{2}+p_{3}=100 \%\right)$.

After all the subjects had filled out the option sheet, Stage 3 began. In Stage 3, the monitor had a subject choose one slip of paper out of an envelope that contained 40 slips of paper, numbered from 1 to 40 . The number on the slip of paper determined which of the 40 options on the option sheet would be played. For example, if slip \#6 was drawn, everyone in the experiment played the option he/she had circled for the pair \#6 on his/her option sheet. Once the option to be played was determined, a different subject then drew a slip of paper from a different envelope that contained 100 slips of paper, numbered 1 to 100 . The number on this slip of paper determined the actual outcome of the option: $-\$ 80,-\$ 30$, or $\$ 0$. Continuing with our example, suppose Lottery A (option \#6) is to be played, thus, $P 1=5 \%, P 2=75 \%, P 3=20 \%$. If the slip of paper drawn is numbered between 1 and 5 , event 1 obtains, so that the subject loses $\$ 80$; if the slip of paper is numbered between 6 and 80 , he loses $\$ 30$; or if a slip is numbered between 81 and 100 , a $\$ 0$ outcome obtains.

In the fourth and final stage, each subject was paid his or her take-home earnings in cash and was asked a few follow-up questions. For example, we probed into whether they interpreted the stakes as large and whether they had understood the experimental instructions.

\section{Experimental results}

Before discussing the formal results of our econometric analysis, we first present some summary information. For each of the 40 lottery comparisons, we identified the percentage of subjects within each cohort (students or CEOs) that indicated a preference for option $A$ over option $B$, and then computed the difference between the fraction of CEOs that preferred option $A$ and the fraction of students that preferred option A. For each of the 40 comparisons, we also calculated the difference between the probability ascribed to the worst outcome under the two options (i.e., $\mathbf{p}_{1 d}=\mathbf{p}_{1}^{\mathrm{A}}-\mathbf{p}_{1}^{\mathrm{B}}$, where $\mathbf{p}_{1}^{k}$ is the probability ascribed to event 1 under option $k=\mathrm{A}$ or B). A graphical representation of the relation between these two differences is contained in Fig. 2. In that diagram, we plot the difference in probabilities, $\mathbf{p}_{1 d}$, on the $x$-axis, and the difference between the fraction of CEOs and the fraction of students selecting option A for a given comparison (denoted aved) on the $y$-axis. A trend line is overlaid on this scatter plot. While this characterization of the data is quite rough, it does point to an important relationship. Specifically, there seems to be an indication that students are slightly less likely than CEOs to choose options with a larger probability on the worst outcome. This might indicate an overall pattern of students exhibiting a greater degree of risk aversion than CEOs, or it might be associated with differences in tendencies to exhibit nonexpected utility maximization between the two groups.

To better understand the explanatory power of each possibility, we first analyze a regression model that assumes subject behavior is consistent with expected utility maximization. If subject $i$ makes 


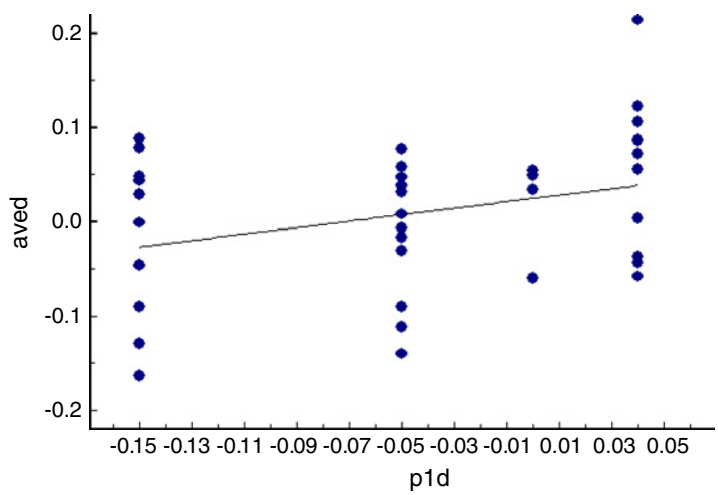

Fig. 2. Differences in tendency to choose option A, CEOs vs. students.

his/her choice on the basis of expected utility, then the criterion for selecting option $\mathrm{A}$ is

$\left(\mathbf{p}_{1}^{\mathrm{A}}-\mathbf{p}_{1}^{\mathrm{B}}\right) u_{i 1}+\left(\mathbf{p}_{2}^{\mathrm{A}}-\mathbf{p}_{2}^{\mathrm{B}}\right) u_{i 2}+\left(\mathbf{p}_{3}^{\mathrm{A}}-\mathbf{p}_{3}^{\mathrm{B}}\right) u_{i 3}>0$,

where $\mathbf{p}_{j}^{k}$ is the probability that event $j=1,2$ or 3 will occur under option $k=\mathrm{A}$ or $\mathrm{B}$, and $u_{i j}$ is the von Neumann-Morgenstern (VNM) utility that agent $i$ ascribes to event $j$. Since probabilities must sum to one, we can simplify the expression on the left side of Eq. (2). Moreover, because the VNM utility function is only uniquely defined up to a monotonic transformation, we impose the normalization $u_{i 1}=0$. The resulting criterion becomes

$u_{i 3}\left(\mathbf{p}_{3}^{\mathrm{A}}-\mathbf{p}_{3}^{\mathrm{B}}\right)+u_{i 2}\left(\mathbf{p}_{3}^{\mathrm{B}}-\mathbf{p}_{3}^{\mathrm{A}}+\mathbf{p}_{1}^{\mathrm{B}}-\mathbf{p}_{1}^{\mathrm{A}}\right)>0$.

We note that a measure of the risk aversion associated with agent $i^{\prime}$ V VNM utility function is ${ }^{7}$

$q_{i}=u_{i 3} / u_{i 2}$.

To obtain information on agents' risk attitudes, we use a logit estimation approach. ${ }^{8}$ Such an approach produces estimates of the parameters $u_{i 3}$ and $u_{i 2}$ for each agent $i$; we then construct the index of risk aversion $q_{i}$ using Eq. (4). Following this approach for each of the subjects in our sample yields a set of estimates of risk attitudes for the entire population. The main question of interest using this approach is whether students tend to exhibit greater risk aversion than do CEOs. To evaluate this hypothesis, we compare the average estimated measures of risk aversion between the two groups. The relevant information for this test is contained in Table 1 .

The key finding in Table 1 is that there is no evidence of a statistically important difference in risk attitudes between CEOs and students, assuming agents' behavior is consistent with the expected utility paradigm. With that observation in mind, we performed a more detailed evaluation of subjects' risk attitudes.

For these purposes, we ran a set of OLS regressions, all of which used the induced measure of the subject's risk attitude as the dependent variable. Explanatory variables are taken from the ancillary data collected in our post-experiment survey (see Appendix B). The first regression, reported in the second column of Table 2 ,

\footnotetext{
7 The index of absolute risk aversion is typically defined by the ratio of second derivative to first derivative; given the discrete nature of our problem, that is approximately $\left[\left(u_{i 3}-u_{i 2}\right) /\left(x_{3}-x_{2}\right)-\left(u_{i 2}-u_{i 1}\right) /\left(x_{2}-x_{1}\right)\right] /\left(u_{i 2}-u_{i 1}\right) /\left(x_{2}-x_{1}\right)$. With the normalization $u_{i 1}=0$, this approximation can be reduced to $\left(u_{i 3} / u_{i 2}\right)\left[\left(x_{2}-\right.\right.$ $\left.\left.x_{1}\right) /\left(x_{3}-x_{2}\right)\right]-\left(x_{3}-x_{1}\right) /\left(x_{3}-x_{2}\right)$. As the fractions involving differences in the $x$ 's are constant across subjects, it follows that the ratio $u_{i 3} / u_{i 2}$ summarizes the relevant information on agent $i$ 's aversion to risk.

8 One can think of this approach as emerging naturally from a random utility model, wherein the agent's true criterion is to choose option A when the left-hand side of Eq. (3) exceeds a random variable that follows the logistic distribution.
}

Table 1

Comparison of average estimated risk indices, CEOs vs. students.

\begin{tabular}{lll}
\hline & CEOs & Students \\
\hline Average value & 1.670 & 1.528 \\
Population s.e. & 1.161 & 0.6495 \\
s.e. of mean & 0.0430 & 0.0072
\end{tabular}

Note: $t$-statistic on differences in means $=0.8049$. The table population estimates are derived from Eq. (4). Note that these estimates are garnered from logit estimation that assumes subject behavior is consistent with expected utility maximization.

included information on gender, whether the subject had formal training in statistics (coded as a 1 if yes, otherwise 0 ), family income, and whether the subject was from the CEO pool (coded as a 1 for CEOs, otherwise 0). Empirical results from this model continue to suggest a lack of significant difference between subject pools. That said, the coefficients on gender, statistics, and CEO are each qualitatively larger than their respective standard errors, hinting at the possibility that a different specification might uncover a significant effect. With this in mind, we consider three variants of this baseline specification, each of which allows for slope differences as well as intercept heterogeneity between subject pools. These are the regressions listed as models 2, 3, and 4 in Table 2.

Important slope differences do emerge for statistics in each variant; there is also some evidence of a potentially important difference in slopes for gender. With respect to statistics, it appears that CEOs have significantly smaller risk attitudes than students, as evidenced by the negative coefficient on the interaction effect. Alternatively, there is some indication that male CEOs are more risk averse than their female counterparts, though the latter group is not well represented in our sample.

As indicated above, however, there is considerable experimental evidence that suggests the expected utility paradigm may not be valid. Accordingly, we investigate an expanded discrete choice model where we allow (i) divergences from the expected utility model and (ii) differences across subjects. Because we are interested in identifying the importance of non-linear effects, a natural approach is to specify $V_{k}$ as a non-linear function of the probabilities. In particular, we assume that the representation $V$ is a cubic function of the probabilities. ${ }^{9}$ This may be regarded as a third-order Taylor's series approximation to a more general non-linear form. We parameterize the cubic as:

$$
\begin{aligned}
V(\mathbf{p})= & \alpha+\beta_{1} p_{1}+\beta_{2} p_{3}+\beta_{3} p_{1}^{2}+\beta_{4} p_{1} p_{3}+\beta_{5} p_{3}^{2} \\
& +\beta_{6} p_{1}^{3}+\beta_{7} p_{1}^{2} p_{3}+\beta_{8} p_{1} p_{3}^{2}+\beta_{9} p_{3}^{3} .
\end{aligned}
$$

Let $Y_{1}=q_{1}-p_{1}, Y_{2}=q_{3}-p_{3}, Y_{3}=q_{1}^{2}-p_{1}^{2}, Y_{4}=q_{1} q_{3}-p_{1} p_{3}$, $Y_{5}=q_{3}^{2}-p_{3}^{2}, Y_{6}=q_{1}^{3}-p_{1}^{3}, Y_{7}=q_{1}^{2} q_{3}-p_{1}^{2} p_{3}, Y_{8}=q_{1} q_{3}^{2}-p_{1} p_{3}^{2}$, and $Y_{9}=q_{3}^{3}-p_{3}^{3}$. Based on this specification, the agent prefers lottery $\mathbf{p}$ over lottery $\mathbf{q}$ if

$$
\begin{aligned}
\varepsilon> & \beta_{1} Y_{1}+\beta_{2} Y_{2}+\beta_{3} Y_{3}+\beta_{4} Y_{4}+\beta_{5} Y_{5} \\
& +\beta_{6} Y_{6}+\beta_{7} Y_{7}+\beta_{8} Y_{8}+\beta_{9} Y_{9},
\end{aligned}
$$

where $\varepsilon$ is a disturbance term that captures unobservable features.

The approach we take towards identifying summary information for each group is based on the average agent. Under this approach, we regard each individual's taste parameters (the coefficients in our regression) as drawn from a population; this approach is termed "mixed Logit" (Revelt and Train, 1998; Train, 1998, 1999; McFadden and Train, 2000). Under the mixed Logit approach, the

\footnotetext{
9 Chew et al. (1991) were the first to propose the quadratic utility approach. They replace the independence axiom with the weaker mixture symmetry axiom that allows for indifference curves to be non-linear so that predicted behavior matches up reasonably well with observed behavior. We generalize their approach.
} 
Table 2

OLS regression analysis of risk attitudes.

\begin{tabular}{|c|c|c|c|c|}
\hline \multirow[t]{2}{*}{ Regressor } & \multicolumn{4}{|l|}{ Regression model } \\
\hline & 1 & 2 & 3 & 4 \\
\hline Male & $0.1761(0.1651)$ & $0.1287(0.1651)$ & & \\
\hline Stat. & $-0.2930(0.1560)$ & $-0.0836(0.1806)$ & & \\
\hline Income & $2.71 \mathrm{E}-08(2.03 \mathrm{E}-08)$ & & & \\
\hline CEO & $0.2802(0.1947)$ & $0.7590^{* * * *}(0.2809)$ & $0.5417^{*}(0.2861)$ & $0.7308^{* * * *}(2.669)$ \\
\hline Male ${ }^{*}$ CEO & & $1.330^{*}(0.8068)$ & $1.233(0.7948)$ & $1.459^{*}(0.7857)$ \\
\hline Stat*CEO & & $-0.8807^{* *}(0.3643)$ & $-0.9521^{* * *}(0.3130)$ & $-0.9643^{* * * *}(0.3147)$ \\
\hline Income*CEO & & & $4.97 \mathrm{E}-08(3.24 \mathrm{E}-08)$ & \\
\hline Constant & $1.491^{* * * *}(0.1194)$ & $1.499^{* * * *}(0.1159)$ & $1.528^{* * *}(0.0805)$ & $1.528^{* * * *}(0.0805)$ \\
\hline$R^{2}$ & 0.057 & 0.104 & 0.097 & 0.097 \\
\hline
\end{tabular}

Notes: Standard errors in parentheses.

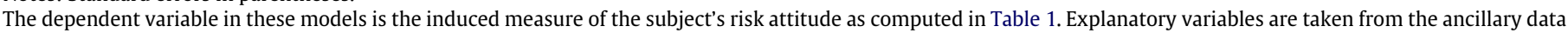
collected in our post-experiment survey, as described in the text.

"Significant at $10 \%$ level or better.

** Significant at $5 \%$ level or better.

*** Significant at $1 \%$ level or better.

Table 3

Mixed LOGIT results, cubic version.

\begin{tabular}{|c|c|c|c|c|}
\hline \multirow[t]{2}{*}{ Regressor } & \multicolumn{2}{|l|}{ Students } & \multicolumn{2}{|l|}{ CEOs } \\
\hline & First moment & Second moment & First moment & Second moment \\
\hline$Y_{1}$ & $111.5^{* * *}(15.13)$ & $1.317(1.811)$ & $115.5^{* * *}(25.76)$ & $0.216(0.611)$ \\
\hline$Y_{2}$ & $0.937(0.647)$ & $0.2609(0.355)$ & $2.211^{*}(1.327)$ & $0.065(0.208)$ \\
\hline$Y_{3}$ & $-1542^{* * *}(205.4)$ & $22.11^{* * *}(5.74)$ & $-1584^{* * *}(343.1)$ & $7.092^{* * * *}(3.267)$ \\
\hline$Y_{4}$ & $-0.257(2.357)$ & $0.030(0.726)$ & $2.406(5.797)$ & $1.913(1.668)$ \\
\hline$Y_{5}$ & $-0.206(0.893)$ & $1.206^{* * * *}(0.504)$ & $-1.375(1.944)$ & $1.713^{* * *}(0.717)$ \\
\hline$Y_{6}$ & $5003^{* * *}(673.7)$ & $1.634(26.19)$ & $5181^{* * *}(1119)$ & $50.11^{* * *}(11.56)$ \\
\hline$Y_{7}$ & $-7.965(20.02)$ & $14.70(11.55)$ & $-5.178^{*}(2.720)$ & $0.924(1.007)$ \\
\hline$Y_{8}$ & $4.609(6.577)$ & $2.460(2.354)$ & $9.315(8.597)$ & $3.090(2.929)$ \\
\hline$Y_{9}$ & $-0.057^{* *}(0.860)$ & $0.044(0.651)$ & $-1.198(1.524)$ & $0.099(0.382)$ \\
\hline Log-likelihood statistic & \multirow{2}{*}{\multicolumn{2}{|c|}{$\begin{array}{l}-2600.41 \\
\quad 45.28(5 \%=28.87 ; 1 \%=34.81)\end{array}$}} & \multirow{2}{*}{\multicolumn{2}{|c|}{-750.14}} \\
\hline Test statistic on $H_{0}$ (no differences) & & & & \\
\hline
\end{tabular}

Notes: Asymptotic standard errors in parentheses.

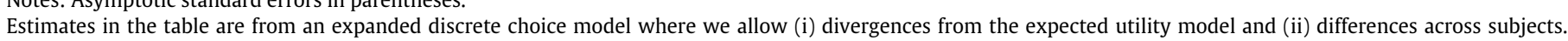
Because we are interested in identifying the importance of non-linear effects, we assume a representation that is a cubic function of the probabilities (see Eq. (5)).

* Significant at $10 \%$ level or better.

** Significant at $5 \%$ level or better.

**** Significant at $1 \%$ level or better.

econometrician identifies the sample mean of the coefficient vector. This mean vector then provides the summary information for the cohort, which we use to identify the behavior of a typical subject in each cohort.

The vector $\left(\beta_{1}, \ldots, \beta_{9}\right)$ summarizes each agent's tastes, which we regard as a draw from a multi-variate distribution. Once the distribution for this vector is specified, ${ }^{10}$ the joint likelihood function can be made explicit. This likelihood function depends on the first two sample moments of the distribution over the parameters, and the stipulated distribution over the error term (e.g., extreme value for the logit application). Estimates of the mean and standard error parameter vectors are then obtained through maximum likelihood estimation.

Unfortunately, exact maximum likelihood estimation is generally impossible (Revelt and Train, 1998; Train, 1998). The alternative is to numerically simulate the distribution over the parameters, use the simulated distribution to approximate the true likelihood function, and then maximize the simulated likelihood function.

Table 3 shows the results from such a procedure; we report estimated mean and standard error parameter vectors for each cohort. For students, the mean population effect for the two non-linear terms $Y_{3}$ and $Y_{6}$ (corresponding to the squared and cubic terms in $\mathbf{p}_{1}$ ) are statistically significant at the $p<0.01$ level. In addition, the

$\overline{10}$ We assume the parameter vector is multi-normally distributed. population standard error associated with the variables $Y_{3}$ and $Y_{5}$ is also significant at the $p<0.01$ level, indicating the presence of important heterogeneities among the population of students with respect to the quadratic term in $\mathbf{p}_{1}$. Each of these parameter estimates is also significant at the $p<0.01$ level for CEOs; in addition, the mean effects associated with the variables $Y_{2}$ and $Y_{7}$ are also statistically significant at better than the $p<0.10$ level, and the standard error associated with the variable $Y_{5}$ is significant at better than the $p<0.05$ level. A key point in these estimates is that many of the parameters corresponding to the non-linear effects are both numerically and statistically important. We infer that the expected utility paradigm does not do a particularly good job of explaining the data from our experiment, either for students or for CEOs.

We are also interested in possible differences between the behavior of students and CEOs. To investigate the hypothesis of statistically indistinguishable behavior, we compare the maximized likelihood function under the restriction that the mean parameter vector is identical for the two cohorts against the corresponding maximal value of the likelihood function when we allow for differences between the two cohorts. We report this statistic at the bottom of Table 3. Under the null hypothesis that behavior is indistinguishable between the cohorts, the test statistic (twice the difference between the maximal log-likelihood values) follows a central chi-square distribution with number of degrees of freedom equal to the number of restrictions. In the case at hand there are 18 restrictions (the first two moments are restricted to be equal for 
Table 4

Mixed LOGIT results, quadratic version.

\begin{tabular}{|c|c|c|c|c|}
\hline \multirow[t]{2}{*}{ Regressor } & \multicolumn{2}{|l|}{ Students } & \multicolumn{2}{|l|}{ CEOs } \\
\hline & First moment & Second moment & First moment & Second moment \\
\hline$Y_{1}$ & $2.140(1.862)$ & $0.152(2.409)$ & $5.631^{*}(2.250)$ & $0.541(0.658)$ \\
\hline$Y_{2}$ & $-0.280(0.488)$ & $0.161(1.304)$ & $0.401(1.173)$ & $0.061(0.219)$ \\
\hline$Y_{3}$ & $-28.29^{* *}(8.227)$ & $22.99^{* *}(3.351)$ & $-37.11^{* *}(11.69)$ & $11.35^{* *}(3.418)$ \\
\hline$Y_{4}$ & $-2.640(1.744)$ & $0.532(1.015)$ & $-4.929(3.937)$ & $0.774(0.582)$ \\
\hline$Y_{5}$ & $1.889^{* *}(0.682)$ & $0.834(0.959)$ & $0.983(1.458)$ & $1.584^{*}(0.692)$ \\
\hline Log-likelihood statistic & -2683.90 & & -777.00 & \\
\hline Test statistic on $H_{0}$ (no impact from cubic terms) & $166.98^{* *}$ & & $53.72^{* *}$ & \\
\hline
\end{tabular}

Notes: Asymptotic standard errors in parentheses.

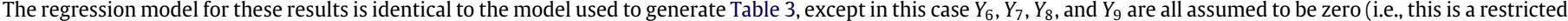
quadratic regression).

" Significant at $5 \%$ level or better.

Significant at $1 \%$ level or better.

the two cohorts for each of the nine parameters). As our test statistic is substantially larger than conventional critical values, we conclude that there are statistically important differences in behavior between the two cohorts.

As aforementioned, many of the earlier experimental analyses of possible deviations from the expected utility paradigm focused on representations that were quadratic in probabilities. Such representations can be nested within our analysis; if the coefficients on the terms $Y_{6}, Y_{7}, Y_{8}$, and $Y_{9}$ are all zero. Such a restriction is easily imposed on the analysis, by running a variant of the mixed logit regressions reported in Table 3, excluding the last 4 explanatory variables; the results from this restricted regression are reported in Table 4. One can then test the joint hypothesis that none of these last four coefficients is important by means of a likelihood ratio test. We report this test statistic at the bottom of Table 4, for each of the subject pools. The interesting thing to note here is the null hypothesis - that none of the four coefficients is important - is soundly rejected for each cohort. Accordingly, we believe our results have important implications for possible alternative forms for the representation of agents' preferences. ${ }^{11}$

While the results we discuss above point to statistical differences in behavior, they do not necessarily imply important economic differences. To address this related issue, one must ask whether the regression model that applies to one cohort differs from the regression model for the other cohort in some significant way. We interpret the notion of "significant differences" as meaning the two models would imply different behavior. From a geometric perspective, such differences are manifested in terms of clear differences in the preference maps for the two groups.

To investigate the possibility of such a phenomenon, we used the regression models reported in Table 3 to numerically generate indifference curves within the Machina-Marschak probability triangle. Four such level curves were generated for both students and CEOs. These four curves all begin from the same combination of probabilities $\left(\mathbf{p}_{1}, \mathbf{p}_{3}\right)$, and then trace out the combinations with the same induced level of value, based on the parameters reported in Table 3, for the cohort in question. We plot these sets of level curves in Fig. 3. For each of the four starting combinations of $\left(\mathbf{p}_{1}, \mathbf{p}_{3}\right)$, the solid curve represents the induced level curve for students while the dashed curve represents the induced level curve for CEOs. There are two noteworthy features. First, for probability combinations with middling values of $\mathbf{p}_{3}$ (say, between 0.25 and 0.65 ) and relatively small values of $\mathbf{p}_{1}$ (say, smaller than 0.15 ), ${ }^{12}$

\footnotetext{
11 A referee suggested that Yaari's (1987) dual model might provide such an explanation. While the spirit of Yaari's approach might be apropos, a literal application is not: Yaari's model leads to a representation that is linear in income or wealth; as we shall see below this does not appear to be consistent with our results.

12 We note that this range of probability combinations largely conforms to the range of probabilities to which subjects were exposed in our experimental design.
}

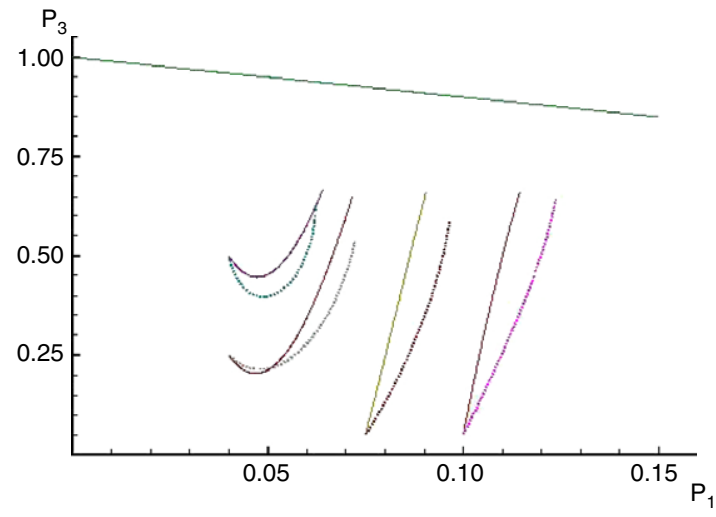

Fig. 3. Level curves implied by cubic representation over lotteries. (Students' curves are solid, CEOs' curves dashed.)

the level curves for CEOs tend to be flatter, and to lie below the level curves for students. Accordingly, CEOs would generally accept a smaller increase in $\mathbf{p}_{3}$ for a given increase in $\mathbf{p}_{1}$, for this range of probability combinations. This phenomenon is roughly the same as the idea that CEOs are "less risk averse" than students, though strictly speaking that related notion would make sense only in the context of the expected utility model. Second, it appears that the level curves for CEOs are more convex than the level curves for students. Thus, when we look at probability combinations closer to the counter-diagonal, the level curves for CEOs have a larger slope than the level curves for students, suggesting that CEOs may exhibit behavior akin to greater aversion to risk at probability combinations where $p_{2}$ is relatively small. This second phenomenon seems most marked for the level curves starting from the combination $\mathbf{p}_{1}=0.04, \mathbf{p}_{3}=0.5$ (the pair of curves highest up in the triangle).

It is interesting to contrast this observation with earlier studies, which tended to find that the most important departures from the expected utility paradigm appear in the corners of the triangle, where one probability is quite large and the others quite small. Our results would seem to suggest that CEOs are relatively more likely to exhibit a similar behavior.

\section{A monetary interpretation}

In this section, we use results from the mixed logit model to investigate a functional form that allows us to infer willingness to pay for a specified change in a lottery faced by the average subject. This discussion is motivated by the following idea: Suppose an agent's choices are consistent with the expected utility paradigm. Then we can use the data on his choices to estimate a linear 
representation over probabilities, and this linear form can be used to infer a von Neumann-Morgenstern utility function over prizes. If the lotteries in question are defined over three prizes, as in our experiments, the inferred utility function is quadratic. This suggests an interpretation with non-linear representations over probabilities wherein the parameters on the various polynomial terms involving probabilities can be linked to some function of the associated prize. We can then use this link between parameters and prize to estimate the representative agent's ex ante willingness to pay for a change in risk.

In our application, with a cubic representation over probabilities, there are 18 terms involving probabilities:

$$
\begin{aligned}
V(\mathbf{p} ; \mathbf{y})= & u_{1} p_{1}+u_{2} p_{2}+u_{3} p_{3}+u_{4} p_{1}^{2}+u_{5} p_{2}^{2}+u_{6} p_{3}^{2} \\
& +u_{7} p_{1} p_{2}+u_{8} p_{1} p_{3}+u_{9} p_{2} p_{3}+u_{10} p_{1}^{3} \\
& +u_{11} p_{1}^{2} p_{2}+u_{12} p_{1}^{2} p_{3}+u_{13} p_{1} p_{2}^{2}+u_{14} p_{1} p_{3}^{2} \\
& +u_{15} p_{2}^{3}+u_{16} p_{2}^{2} p_{3}+u_{17} p_{2}^{2} p_{3}+u_{18} p_{3}^{3},
\end{aligned}
$$

where the $u_{i}$ 's are functions of the prizes $y_{i}$. Since the probabilities sum to one, we reduce this specification to nine parameters, as in Eq. (5). The resultant parameters (the $\beta$ 's in Eq. (5)) are therefore tied to the original functions in a specific manner. Next, we propose a functional relation between the parameters $u_{i}$ in Eq. (7) and the associated prizes. The functional representation we propose is motivated by the observation that the highest-order function that can be employed with three prizes is quadratic, and by the constraint that there are only nine parameters estimated in the mixed logit application. Accordingly, we explore the functional relations:

$$
\begin{aligned}
& u_{i}=\gamma_{1} y_{i}+\gamma_{2} y_{i}^{2}, \quad i=1,2, \text { and } 3 ; \\
& u_{i}=\phi_{1} y_{i-3}+\phi_{2} y_{i-3}^{2}, \quad i=4,5, \text { and } 6 ; \\
& u_{7}=\eta y_{1} y_{2}, \quad u_{8}=\eta y_{1} y_{3}, \quad \text { and } u_{9}=\eta y_{2} y_{3} ; \\
& u_{10}=\omega_{1} y_{1}+\omega_{1} y_{1}^{2}, \quad u_{15}=\omega_{1} y_{2}+\omega_{1} y_{2}^{2}, \quad \text { and } \\
& u_{18}=\omega_{1} y_{3}+\omega_{1} y_{3}^{2} ; \\
& u_{11}=\xi_{1} y_{1} y_{2}+\xi_{2} y_{1}^{2} y_{2}, \quad u_{12}=\xi_{1} y_{1} y_{3}+\xi_{2} y_{1}^{2} y_{3}, \\
& u_{13}=\xi_{1} y_{1} y_{2}+\xi_{2} y_{1} y_{2}^{2}, \\
& u_{14}=\xi_{1} y_{1} y_{3}+\xi_{2} y_{1} y_{3}^{2}, \\
& u_{17}=\xi_{1} y_{2} y_{3}+\xi_{2} y_{2} y_{3}^{2} .
\end{aligned}
$$

The goal is to obtain estimates of the parameters $\gamma_{1}, \gamma_{2}, \phi_{1}, \phi_{2}, \eta$, $\omega_{1}, \omega_{2}, \xi_{1}$, and $\xi_{2}$ from the estimated parameters $\beta_{1}$ through $\beta_{9}$, for both students and CEOs. Such a process is tedious, involving substantial algebraic manipulation; in the interest of brevity we do not reproduce these calculations here. Table 5 lists the estimates of the nine new parameters of interest, based on the result of those manipulations and the parameter estimates from Table 3. Interestingly, these representations appear to be quite similar for the two groups. As we will see below, the similarity in these parameter vectors induces strong similarities in monetary valuations. ${ }^{13}$

Armed with these values, we describe a monetary value of a policy change. For example, suppose a certain intervention could reduce the probability of the worst outcome from $p_{1}$ to $p_{1}^{\prime}$, with an offsetting increase in the probability of the middle outcome from $p_{2}$ to $p_{2}^{\prime}$. The monetary value of this intervention is the value of OP that solves

$V\left(p_{1}, p_{2}, p_{3} ; \mathbf{y}\right)=V\left(p_{1}^{\prime}, p_{2}^{\prime}, p_{3} ; \mathbf{y}-\mathrm{OP}\right)$.

\footnotetext{
13 We also conducted a parallel but restricted investigation, based on the quadratic representation whose estimates are given in Table 4 . The monetary value induced by this alternative investigation is similar to that reported in the text, and is
} available from the authors on request.
Table 5

Implied coefficients on money in non-linear representation, students vs. CEOs.

\begin{tabular}{lcc}
\hline Parameter & Estimated value for students & Estimated value for CEOs \\
\hline$\gamma_{1}$ & -1236.6 & -1281.8 \\
$\gamma_{2}$ & 11.484 & 11.902 \\
$\phi_{1}$ & 4.5372 & 4.7003 \\
$\phi_{2}$ & 446.13 & 462.27 \\
$\eta$ & -2.3813 & -2.4681 \\
$\omega_{1}$ & -212.11 & -219.56 \\
$\omega_{2}$ & 1.2434 & 1.2863 \\
$\xi_{1}$ & -2.5193 & -2.6076 \\
$\xi_{2}$ & -0.00011 & -0.00012 \\
\hline
\end{tabular}

The table reports estimates of the parameters $\gamma_{1}, \gamma_{2}, \phi_{1}, \phi_{2}, \eta, \omega_{1}, \omega_{2}, \xi_{1}$, and $\xi_{2}$ from the estimated parameters $\beta_{1}$ through $\beta_{9}$, for both students and CEOs. Such a process is tedious, involving substantial algebraic manipulation; but it builds on the parameter estimates from Table 3.

The monetary value $\mathrm{OP}$ is the agent's ex ante willingness to pay, irrespective of the ultimate state of nature that obtains, to influence the change in probabilities.

We consider two examples to illustrate the point. First, suppose we start from the combination $\left(p_{1}, p_{2}, p_{3}\right)=(0.1,0.3,0.6)$ and reduce $p_{1}$ by 0.05 , moving to $\left(p_{1}, p_{2}, p_{3}\right)=(0.05,0.3,0.6)$. This change increases the expected value of the lottery by $\$ 2.50$. Using the parameters in Table 5, we calculate the ex ante monetary value of this change as OP $=\$ 1.7028$ for both students and CEOs. Similarly, a change that completely eliminates the risk associated with the worst outcome (i.e., moving 0.10 from $p_{1}$ to $p_{2}$ ) has an expected value of $\$ 5$. Based on the parameters in Table 3 , we calculate that the monetary value of this change is OP $=\$ 3.5340$ for both students and CEOs. For both hypothetical changes, then, we conclude that there is no discernible difference in willingness to pay for the two groups.

As a second example, suppose the initial combination is $\left(p_{1}\right.$, $\left.p_{2}, p_{3}\right)=(0.05,0.45,0.5)$; again, we reduce $p_{1}$ by $50 \%$ (here, to $0.025)$, moving to $\left(p_{1}, p_{2}, p_{3}\right)=(0.025,0.45,0.5)$. This change increases the expected value of the lottery by $\$ 1.25$. Using the parameters in Table 3, we calculate the ex ante monetary value of this change as OP $=\$ 1.3504$ for both students and CEOs. Similarly, a change that completely eliminates the risk associated with the worst outcome (i.e., moving 0.10 from $p_{1}$ to $p_{2}$ ) has an expected value of $\$ 5$. Based on the parameters in Table 5 , we calculate that the monetary value of this change is OP $=\$ 2.6922$ for both students and CEOs. Again, we conclude that there is no discernible difference in willingness to pay for the two groups.

\section{Concluding remarks}

Small probability, high loss events are ubiquitous. Whether individual behavior in such situations follows the postulates of expected utility theory merits serious consideration from both a positive and normative perspective since it remains the dominant paradigm used throughout the public sector and it remains the most popular model of choice under uncertainty. In this study, we combined high stakes experiments with a unique subject pool CEOs - to examine individual preferences over lotteries for losses. Examining more than 1000 (4000) CEO (student) lottery choices, we found significant departures from expected utility theory both in the student data as well as in the CEO data. In particular, our findings suggest that a policy approach based solely on expected benefits and expected costs would significantly understate society's actual willingness to pay to reduce risk in low probability, high loss events. Our econometric results indicate that representations of the typical subject are quite similar for the two groups. Specifically, based on the estimated parameters, we find that willingness to pay to reduce the chance of the worst event for a typical CEO is very similar to the corresponding willingness to pay for a 
typical student. Yet we do find interesting subtle differences in behavior across subject pools.

This study represents but a first step outside of the typical laboratory exercise to more fully understand behavior over small probability, high loss events. While we have explored how results vary across students and CEOs, representativeness of the situation has been put on the sidelines. Given that List (2006) argues that representativeness of the environment, rather than representativeness of the sampled population, is the most crucial variable in determining the generalizability of results for a large class of experimental laboratory games, it is important to note that we examine behavior in one highly stylized environment, potentially far removed from domains and decision tasks present in certain markets. We trust that future research will soon begin these important next steps.

\section{Acknowledgements}

Thanks to Colin Camerer, Glenn Harrison, Kerry Smith, Chris Starmer, Robert Sugden, David Zilberman, and two referees for supplying comments. We thank Kenneth Train for supplying the GAUSS program with which we conducted our empirical estimation. An earlier version of this paper was presented at the World Conference for Environmental and Natural Resource Economists and the Southern Economic Association Meetings.

\section{Appendix A. Experimental instructions}

\section{Instructions}

Welcome. This is an experiment in decision making that will take about an hour to complete. You will be paid in cash for participating at the end of the experiment. How much you earn depends on your decisions and chance. Please do not talk and do not try to communicate with any other subject during the experiment. If you have a question, please raise your hand and a monitor will come over. If you fail to follow these instructions, you will be asked to leave and forfeit any moneys earned. You can leave the experiment at any time without prejudice. Please read these instructions carefully, and then review your answers on the Questions and Answers page.

An overview: You will be presented with 40 pairs of options. For each pair, you will pick the option you prefer. After you have made all 40 choices, you will then play one of the 40 options to determine your take-home earnings.

\section{The experiment}

Stage \#1: The option sheet: After filling out the waiver and the survey forms, the experiment begins. You start with $\$ 100$, and your choices and chance affect how much of this money you can keep as your take-home earnings.

You will be given an option sheet with 40 pairs of options. For each pair, you will circle the option you prefer. Each option is divided into 3 probabilities:

$P 1$ is the probability you will lose $\$ 80$;

$P 2$ is the probability you will lose $\$ 30$; and

$P 3$ is the probability you will lose $\$ 0$.

For each option, the three probabilities always add up to $100 \%$ $(P 1+P 2+P 3=100 \%)$. For example, if an option has $P 1=20 \%$, $P 2=50 \%$ and $P 3=30 \%$, this implies you have a $20 \%$ chance to lose $\$ 80$, a $50 \%$ chance to lose $\$ 30$, and a $30 \%$ chance to lose $\$ 0$.

On your option sheet, you circle your preferred option for each of the 40 pairs. For example, consider the pair of options, A and $B$, presented below. Suppose after examining the pair of options carefully, you prefer option A to B - then you would circle A (as shown below). If you prefer B, you would circle B.

$$
\begin{array}{ll}
A & \text { B } \\
P 1=10 \%, P 2=20 \%, & P 1=20 \%, P 2=20 \%, \\
P 3=70 \% & P 3=60 \%
\end{array}
$$

Stage \#2: The tan pitcher: After filling out your option sheet, please wait until the monitor calls you to the front of the room. When called, bring your waiver form, survey, and option sheet with you.

On the front table is a tan pitcher with 40 chips inside, numbered 1-40. The number on the chip represents the option you will play from your option sheet. You will reach into the tan pitcher without looking at the chips, and pick out a chip. The number on the chip determines which option you will play to determine your take-home earnings. For example, if you draw chip \#23, you will play the option you circled for the pair \#23 on your option sheet.

Stage \#3: The blue pitcher: After you have selected the option you will play, you then draw a different chip from a second pitcher - the blue pitcher. The blue pitcher has 100 chips, numbered $1-100$. The number on the chip determines the actual outcome of the option - a loss of either $\$ 80, \$ 30$, or $\$ 0$.

For example, if your option played has

$$
\begin{aligned}
& P 1=10 \% \\
& P 2=50 \% \\
& P 3=40 \%,
\end{aligned}
$$

then if you pick a chip numbered between 1 and 10 , you lose $\$ 80$; if you pick a chip between 11 and 60 , you lose $\$ 30$; or if you pick a chip between 61 and 100, you lose $\$ 0$.

If instead, your option played has

$$
\begin{aligned}
& P 1=20 \% \\
& P 2=20 \% \\
& P 3=60 \%,
\end{aligned}
$$

then if you pick a chip between 1 and 20 , you lose $\$ 80$; if you pick a chip between 21 and 40 , you lose $\$ 30$; or if you pick a chip between 41 and 100, you lose $\$ 0$.

Stage \#4: Ending the experiment: After playing the option, you fill out a tax form. The monitor will then hand over your take-home earnings, and you can leave the room.

Now please read through the questions and answers on the next page.

Questions and Answers

1. When I make a choice, I will choose between how many options?

2.

2. I will make how many choices?

40.

3. My initial $\$$ endowment is how much?

$\$ 100$.

4. $P 1$ represents what?

The probability of losing $\$ 80$.

5. $P 2$ represents what?

The probability of losing $\$ 30$.

6. $P 3$ represents what?

The probability of losing $\$ 0$.

7. For each option, the three probabilities sum to what? $100 \%$.

8. What does the number drawn from the tan pitcher represent? The option (1-40) played from your option sheet.

9. What does the number drawn from the blue pitcher represent? The outcome (1-100) of the option played - determining whether you lose either $\$ 80, \$ 30$, or $\$ 0$.

Are there any questions? 


\section{Appendix B. The survey sheet}

1. Social Security Number:

2. Gender: (circle) Male Female

3. Birthdate:__ (month/day/year) Highest Level of School Completed: (please circle) Junior High School High School or Equivalency College or Trade School Graduate or Professional School

4. Courses Taken in Mathematics: (please circle all that apply) College Algebra

Calculus or Business Calculus Linear Algebra

Statistics or Business Statistics

5. Family's Annual Income:

6. Personal Annual Income:

Thank you

\section{Appendix C. The option sheet}

Social Security Number: An Example:

\begin{tabular}{|c|c|c|}
\hline & A & B \\
\hline & $\begin{array}{l}P_{1}=10 \%, P_{2}=20 \% \\
P_{3}=70 \% \\
10 \% \text { chance of } \\
\text { losing } \$ 80 \\
20 \% \text { chance of } \\
\text { losing } \$ 30 \\
70 \% \text { chance of } \\
\text { losing } \$ 0\end{array}$ & $\begin{array}{c}P_{1}=20 \%, P_{2}=20 \%, \\
P_{3}=60 \% \\
20 \% \text { chance of } \\
\text { losing } \$ 80 \\
20 \% \text { chance of } \\
\text { losing } \$ 30 \\
60 \% \text { chance of } \\
\text { losing } \$ 0\end{array}$ \\
\hline \# & A & B \\
\hline 1. & $\begin{array}{l}P_{1}=5 \%, P_{2}=35 \%, \\
P_{3}=60 \%\end{array}$ & $\begin{array}{l}P_{1}=1 \%, P_{2}=40 \% \\
P_{3}=59 \%\end{array}$ \\
\hline 2. & $\begin{array}{l}P_{1}=20 \%, P_{2}=0 \% \\
P_{3}=80 \%\end{array}$ & $\begin{array}{l}P_{1}=20 \%, P_{2}=39 \% \\
P_{3}=41 \%\end{array}$ \\
\hline 3. & $\begin{array}{l}P_{1}=5 \%, P_{2}=35 \% \\
P_{3}=60 \%\end{array}$ & $\begin{array}{l}P_{1}=1 \%, P_{2}=49 \% \\
P_{3}=50 \%\end{array}$ \\
\hline 4. & $\begin{array}{l}P_{1}=5 \%, P_{2}=35 \% \\
P_{3}=60 \%\end{array}$ & $\begin{array}{l}P_{1}=5 \%, P_{2}=55 \%, \\
P_{3}=40 \%\end{array}$ \\
\hline 5. & $\begin{array}{l}P_{1}=5 \%, P_{2}=55 \% \\
P_{3}=40 \%\end{array}$ & $\begin{array}{l}P_{1}=1 \%, P_{2}=69 \% \\
P_{3}=30 \%\end{array}$ \\
\hline 6. & $\begin{array}{l}P_{1}=5 \%, P_{2}=75 \% \\
P_{3}=20 \%\end{array}$ & $\begin{array}{l}P_{1}=20 \%, P_{2}=50 \% \\
P_{3}=30 \%\end{array}$ \\
\hline 7. & $\begin{array}{l}P_{1}=5 \%, P_{2}=55 \% \\
P_{3}=40 \%\end{array}$ & $\begin{array}{l}P_{1}=1 \%, P_{2}=60 \%, \\
P_{3}=39 \%\end{array}$ \\
\hline 8. & $\begin{array}{l}P_{1}=5 \%, P_{2}=75 \% \\
P_{3}=20 \%\end{array}$ & $\begin{array}{l}P_{1}=20 \%, P_{2}=59 \% \\
P_{3}=21 \%\end{array}$ \\
\hline 9. & $\begin{array}{l}P_{1}=5 \%, P_{2}=75 \% \\
P_{3}=20 \%\end{array}$ & $\begin{array}{l}P_{1}=1 \%, P_{2}=89 \%, \\
P_{3}=10 \%\end{array}$ \\
\hline 10. & $\begin{array}{l}P_{1}=5 \%, P_{2}=55 \% \\
P_{3}=40 \%\end{array}$ & $\begin{array}{l}P_{1}=20 \%, P_{2}=30 \% \\
P_{3}=50 \%\end{array}$ \\
\hline 11. & $\begin{array}{l}P_{1}=5 \%, P_{2}=75 \% \\
P_{3}=20 \%\end{array}$ & $\begin{array}{l}P_{1}=1 \%, P_{2}=80 \%, \\
P_{3}=19 \%\end{array}$ \\
\hline 12. & $\begin{array}{l}P_{1}=5 \%, P_{2}=55 \% \\
P_{3}=40 \%\end{array}$ & $\begin{array}{l}P_{1}=20 \%, P_{2}=39 \% \\
P_{3}=41 \%\end{array}$ \\
\hline 13 & $\begin{array}{l}P_{1}=5 \%, P_{2}=35 \% \\
P_{3}=60 \%\end{array}$ & $\begin{array}{l}P_{1}=10 \%, P_{2}=25 \% \\
P_{3}=65 \%\end{array}$ \\
\hline 14. & $\begin{array}{l}P_{1}=5 \%, P_{2}=35 \% \\
P_{3}=60 \%\end{array}$ & $\begin{array}{l}P_{1}=20 \%, P_{2}=10 \% \\
P_{3}=70 \%\end{array}$ \\
\hline 15. & $\begin{array}{l}P_{1}=5 \%, P_{2}=35 \% \\
P_{3}=60 \%\end{array}$ & $\begin{array}{l}P_{1}=10 \%, P_{2}=10 \% \\
P_{3}=80 \%\end{array}$ \\
\hline 16 & $\begin{array}{l}P_{1}=5 \%, P_{2}=35 \% \\
P_{3}=60 \%\end{array}$ & $\begin{array}{l}P_{1}=20 \%, P_{2}=19 \% \\
P_{3}=61 \%\end{array}$ \\
\hline
\end{tabular}

\begin{tabular}{|c|c|c|}
\hline & $A$ & B \\
\hline 17. & $\begin{array}{l}P_{1}=5 \%, P_{2}=55 \%, \\
P_{3}=40 \%\end{array}$ & $\begin{array}{l}P_{1}=10 \%, P_{2}=45 \% \\
P_{3}=45 \%\end{array}$ \\
\hline 18. & $\begin{array}{l}P_{1}=5 \%, P_{2}=75 \%, \\
P_{3}=20 \%\end{array}$ & $\begin{array}{l}P_{1}=10 \%, P_{2}=60 \% \\
P_{3}=30 \%\end{array}$ \\
\hline 19. & $\begin{array}{l}P_{1}=5 \%, P_{2}=55 \%, \\
P_{3}=40 \%\end{array}$ & $\begin{array}{l}P_{1}=10 \%, P_{2}=30 \% \\
P_{3}=60 \%\end{array}$ \\
\hline 20. & $\begin{array}{l}P_{1}=5 \%, P_{2}=75 \%, \\
P_{3}=20 \%\end{array}$ & $\begin{array}{l}P_{1}=10 \%, P_{2}=69 \%, \\
P_{3}=21 \%\end{array}$ \\
\hline 21. & $\begin{array}{l}P_{1}=5 \%, P_{2}=35 \%, \\
P_{3}=60 \%\end{array}$ & $\begin{array}{l}P_{1}=1 \%, P_{2}=44 \%, \\
P_{3}=55 \%\end{array}$ \\
\hline 22. & $\begin{array}{l}P_{1}=10 \%, P_{2}=10 \% \\
P_{3}=80 \%\end{array}$ & $\begin{array}{l}P_{1}=10 \%, P_{2}=49 \% \\
P_{3}=41 \%\end{array}$ \\
\hline 23. & $\begin{array}{l}P_{1}=5 \%, P_{2}=35 \% \\
P_{3}=60 \%\end{array}$ & $\begin{array}{l}P_{1}=1 \%, P_{2}=59 \%, \\
P_{3}=40 \%\end{array}$ \\
\hline 24. & $\begin{array}{l}P_{1}=1 \%, P_{2}=40 \%, \\
P_{3}=59 \%\end{array}$ & $\begin{array}{l}P_{1}=1 \%, P_{2}=79 \%, \\
P_{3}=20 \%\end{array}$ \\
\hline 25. & $\begin{array}{l}P_{1}=5 \%, P_{2}=55 \%, \\
P_{3}=40 \%\end{array}$ & $\begin{array}{l}P_{1}=1 \%, P_{2}=79 \%, \\
P_{3}=20 \%\end{array}$ \\
\hline 26. & $\begin{array}{l}P_{1}=5 \%, P_{2}=75 \%, \\
P_{3}=20 \%\end{array}$ & $\begin{array}{l}P_{1}=20 \%, P_{2}=40 \% \\
P_{3}=40 \%\end{array}$ \\
\hline 27. & $\begin{array}{l}P_{1}=5 \%, P_{2}=55 \%, \\
P_{3}=40 \%\end{array}$ & $\begin{array}{l}P_{1}=1 \%, P_{2}=64 \%, \\
P_{3}=35 \%\end{array}$ \\
\hline 28. & $\begin{array}{l}P_{1}=5 \%, P_{2}=75 \%, \\
P_{3}=20 \%\end{array}$ & $\begin{array}{l}P_{1}=20 \%, P_{2}=55 \% \\
P_{3}=25 \%\end{array}$ \\
\hline 29. & $\begin{array}{l}P_{1}=5 \%, P_{2}=75 \%, \\
P_{3}=20 \%\end{array}$ & $\begin{array}{l}P_{1}=1 \%, P_{2}=99 \%, \\
P_{3}=0 \%\end{array}$ \\
\hline 30. & $\begin{array}{l}P_{1}=5 \%, P_{2}=55 \%, \\
P_{3}=40 \%\end{array}$ & $\begin{array}{l}P_{1}=20 \%, P_{2}=20 \% \\
P_{3}=60 \%\end{array}$ \\
\hline 31. & $\begin{array}{l}P_{1}=5 \%, P_{2}=75 \%, \\
P_{3}=20 \%\end{array}$ & $\begin{array}{l}P_{1}=1 \%, P_{2}=84 \%, \\
P_{3}=15 \%\end{array}$ \\
\hline 32. & $\begin{array}{l}P_{1}=5 \%, P_{2}=55 \%, \\
P_{3}=40 \%\end{array}$ & $\begin{array}{l}P_{1}=20 \%, P_{2}=35 \% \\
P_{3}=45 \%\end{array}$ \\
\hline 33. & $\begin{array}{l}P_{1}=5 \%, P_{2}=35 \%, \\
P_{3}=60 \%\end{array}$ & $\begin{array}{l}P_{1}=10 \%, P_{2}=29 \% \\
P_{3}=61 \%\end{array}$ \\
\hline 34. & $\begin{array}{l}P_{1}=5 \%, P_{2}=35 \%, \\
P_{3}=60 \%\end{array}$ & $\begin{array}{l}P_{1}=20 \%, P_{2}=0 \%, \\
P_{3}=80 \%\end{array}$ \\
\hline 35. & $\begin{array}{l}P_{1}=5 \%, P_{2}=35 \%, \\
P_{3}=60 \%\end{array}$ & $\begin{array}{l}P_{1}=10 \%, P_{2}=20 \% \\
P_{3}=70 \%\end{array}$ \\
\hline 36. & $\begin{array}{l}P_{1}=5 \%, P_{2}=35 \%, \\
P_{3}=60 \%\end{array}$ & $\begin{array}{l}P_{1}=20 \%, P_{2}=15 \% \\
P_{3}=65 \%\end{array}$ \\
\hline 37. & $\begin{array}{l}P_{1}=5 \%, P_{2}=55 \%, \\
P_{3}=40 \%\end{array}$ & $\begin{array}{l}P_{1}=10 \%, P_{2}=49 \% \\
P_{3}=41 \%\end{array}$ \\
\hline 38. & $\begin{array}{l}P_{1}=5 \%, P_{2}=75 \%, \\
P_{3}=20 \%\end{array}$ & $\begin{array}{l}P_{1}=10 \%, P_{2}=50 \% \\
P_{3}=40 \%\end{array}$ \\
\hline 39. & $\begin{array}{l}P_{1}=5 \%, P_{2}=55 \%, \\
P_{3}=40 \%\end{array}$ & $\begin{array}{l}P_{1}=10 \%, P_{2}=40 \% \\
P_{3}=50 \%\end{array}$ \\
\hline 40. & $\begin{array}{l}P_{1}=5 \%, P_{2}=75 \%, \\
P_{3}=20 \%\end{array}$ & $\begin{array}{l}P_{1}=10 \%, P_{2}=65 \% \\
P_{3}=25 \%\end{array}$ \\
\hline
\end{tabular}

\section{References}

Baron, J., 1992. Thinking and Deciding. Cambridge University Press, New York.

Burns, P., 1985. Experience and decisionmaking: A comparison of students and businessmen in a simulated progressive auction. In: Smith, Vernon L. (Ed.), Research in Experimental Economics. JAI, pp. 139-153.

Chew, S., Epstein, L., Segal, U., 1991. Mixture symmetry and quadratic utility. Econometrica 59, 139-163.

Chichilnisky, G., Heal, G., 1993. Global environmental risks. Journal of Economic Perspectives 7, 65-86.

Evans, D., 1997. The role of markets in reducing expected utility violations. Journal of Political Economy 105, 622-636.

Fehr, E., List, J.A., 2004. The hidden costs and returns of incentives-Trust and trustworthiness among CEOS. Journal of the European Economic Association 2 (5), 743-771.

Haigh, M., List, J.A., 2005. Do professional traders exhibit myopic loss aversion? An experimental analysis. Journal of Finance 60 (1), 523-534. 
Harless, D., 1992. Predictions about indifference curves inside the unit triangle: A test of variants of expected utility theory. Journal of Economic Behavior and Organization 18, 391-414.

Harrison, G.W., List, J.A., 2004. Field experiments. Journal of Economic Literature 42, 1009-1055.

Hey, J., 1995. Experimental investigations of errors in decision making under risk. European Economic Review 39, 633-640.

Hey, J., Orme, C., 1994. Investigating generalizations of expected utility theory using experimental data. Econometrica 62, 1291-1326.

Hirshleifer, J., Riley, J.G., 1992. The Analytics of Uncertainty and Information. Cambrdge University Press, New York.

Levitt, S.D., List, J.A., 2007. What do laboratory experiments measuring social preferences tell us about the real world. Journal of Economic Perspectives 21 (2), 153-174.

List, J.A., 2006. Field experiments: A bridge between lab and naturally occurring data. Advances in Economic Analysis \& Policy 6 (2), Article 8. Available at: http://www.bepress.com/bejeap/advances/vol6/iss2/art8.

Lichtenstein, S., et al., 1978. The judged frequency of lethal events. Journal of Experimental Psychology 4, 551-578.

Machina, M., 1987. Choice under uncertainty: Problems resolved and unresolved. Journal of Economic Perspectives 1, 121-154.
Marschak, J., 1950. Rational behavior, uncertain prospects, and measurable utility. Econometrica 18, 111-141.

Mason, C.F., Shogren, J.F., Settle, C., List, J.A., 2005. Investigating risky choices over losses using experimental data. The Journal of Risk and Uncertainty 31 (2), 187-215.

McFadden, D., Train, K., 2000. Mixed MNL models for discrete response. Journal of Applied Econometrics 15, 447-470.

Revelt, D., Train, K., 1998. Mixed logit with repeated choices: Households' choices of appliance efficiency level. Review of Economics and Statistics 53, 647-657.

Starmer, C., 2000. Developments in non-expected utility theory: The hunt for a descriptive theory of choice under risk. Journal of Economic Literature 38 332-382.

Thaler, R., 1992. The Winner's Curse. Free Press, New York.

Train, K., 1998. Recreation demand models with taste differences over people. Land Economics 74, 230-239.

Train, K., 1999. Mixed logit models of recreation demand. In: Kling, C., Herriges, J. (Eds.), Valuing the Environment Using Recreation Demand Models. Elgar Press. Viscusi, W.K, 1992. Fatal Tradeoffs. Oxford University Press, New York.

Yaari, M.E., 1987. The dual theory of choice under risk. Econometrica 55 (1), 95-115. 